\title{
Estudo preliminar: construção do inventário de habilidades sociais para alunos sem fala articulada
}

\author{
Prelimanary study: construction of the inventory of social skills for students \\ without articulated speech
}

Estudio preliminar: construcción del inventario de habilidades sociales para estudiantes sin lenguaje articulado

\section{Patricia Lorena Quiterio}

Professora doutora na Universidade do Estado do Rio de Janeiro, Rio de Janeiro, Rio de Janeiro, Brasil. patricialorenauerj@gmail.com

ORCID - http://orcid.org/0000-0002-4553-6429

\section{Leila Regina d'Oliveira de Paula Nunes}

Professora doutora na Universidade do Estado do Rio de Janeiro, Rio de Janeiro, Rio de Janeiro, Brasil. leilareginanunes@gmail.com

ORCID - http://orcid.org/0000-0003-2012-6973

\section{Eliane Gerk}

Professora doutora na Universidade do Estado do Rio de Janeiro, Rio de Janeiro, Rio de Janeiro, Brasil. elianegerk@gmail.com

ORCID - http://orcid.org/0000-0002-1022-2825

Recebido em 24 de fevereiro 2020

Aprovado em 15 de agosto de 2020

Publicado em 30 de setembro de 2020

\section{RESUMO}

O aluno com deficiência sem fala articulada pode apresentar dificuldade de expressar seus sentimentos e pensamentos de forma eficiente, prejudicando seu desenvolvimento acadêmico e social. Este estudo preliminar objetivou a construção e avaliação do Inventário de Habilidades Sociais para Alunos Sem Fala Articulada, construído com base no Sistema Multimídia de Habilidades Sociais para Crianças, na Escala de Assertividade e nos registros das observações diretas realizadas no ambiente escolar. A etapa inicial envolveu a construção dos 20 itens do instrumento em formato de pranchas com imagens que descrevem situações vivenciadas na escola e em outros contextos interativos por pessoas com deficiência. Como segunda etapa, desenvolveu-se um primeiro estudo experimental, em que quatro alunos de uma escola especial $(M=21 ; d p=2,16)$ que apresentavam paralisia cerebral, sem fala articulada, responderam ao inventário. Na terceira etapa, realizou-se a análise da aplicação e modificação do instrumento. $E$ na quarta etapa, em continuidade ao estudo experimental, oito alunos $(M=13,88$; $d p=6,49)$ com as mesmas características responderam ao inventário. Para testar a validade do instrumento foi aplicado o Teste de Postos com Sinal de Wilcoxon (Ho para $p \leq 0,02)$, comparando-se as respostas dos alunos com as das suas professoras, revelando resultados estatisticamente significantes. A construção do instrumento teve o propósito de uma análise semântica dos itens e a análise em relação à aplicabilidade, à funcionalidade e à acessibilidade correspondeu aos critérios. Além disso, as informações contribuirão para o planejamento e 
http://dx.doi.org/10.5902/1984686X42602

desenvolvimento de programas de promoção das habilidades sociais junto à população com deficiência.

Palavras-chave: Construção de instrumento; habilidades sociais; comunicação alternativa.

\section{ABSTRACT}

Students with disabilities without articulate speech may have difficulty expressing their feelings and thoughts efficiently, impairing their academic and social development. This preliminary study aimed at the construction and evaluation of the Social Skills Inventory for Students Without Articulated Speech, built based on the Multimedia System of Social Skills for Children, on the Assertiveness Scale and on the records of direct observations made in the school environment. The initial stage involved the construction of the 20 instrument items in the format of boards with images that describe situations experienced at school and in other interactive contexts by people with disabilities. As a second step, a first experimental study was developed, in which four students from a special school $(M=21$; $s d=2.16)$ who had cerebral palsy, without articulated speech, responded to the inventory. In the third stage, took place analyzing the application and modifying the instrument. And in the fourth step, in continuity with the experimental study, eight students $(M=13.88$; $s d=6.49)$ with the same characteristics responded to the inventory. To test the instrument's validity, the Wilcoxon Signal Test was applied (Ho for $p \leq 0.02$ ) comparing the students' responses with those of their teachers, revealing statistically significant results. The construction of the instrument had the purpose of a semantic analysis of the items and the analysis in relation to the applicability, functionality and accessibility corresponded to the criteria. In addition, the information will contribute to the planning and development of programs to promote social skills among the population with disabilities.

Keywords: Instrument construction; social skills; alternative communication.

\section{RESUMEN}

Los estudiantes con discapacidades sin lenguaje articulado pueden tener dificultades para expresar sus sentimientos y pensamientos de manera eficiente, lo que perjudica su desarrollo académico y social. Este estudio preliminar tuvo como objetivo la construcción y evaluación del Inventario de Habilidades Sociales para Estudiantes sin Discurso Articulado, basado en el Sistema Multimedia de Habilidades Sociales para Niños, en la Escala de Asertividad y en los registros de observaciones directas realizadas en el entorno escolar. La etapa inicial implicó la construcción de los veinte elementos del instrumento en forma de tableros con imágenes que describen situaciones experimentadas en la escuela y en otros contextos interactivos por personas con discapacidades. Como segundo paso, se desarrolló un primer estudio experimental, en el que cuatro estudiantes de una escuela especial $(M=21$; $s d=2.16)$ que tenían parálisis cerebral, sin lenguaje articulado, respondieron al inventario. En la tercera etapa, tuvo lugar analizar la aplicación y modificar el instrumento. Y en el cuarto paso, en continuidad con el estudio experimental, ocho estudiantes $(M=13.88$; $s d=6.49)$ con las mismas características respondieron al inventario. Para probar la validez del instrumento, se aplicó la prueba de señal de Wilcoxon (Ho para p $\leq 0.02$ ) comparando las respuestas de los estudiantes con las de sus maestros, revelando resultados estadísticamente significativos. La construcción del instrumento tenía el propósito de un análisis semántico de los ítems y el análisis en relación a la aplicabilidad, funcionalidad y accesibilidad correspondía a los criterios. Además, la información contribuirá a la planificación y el desarrollo de programas para promover las habilidades sociales entre la población con discapacidad.

Palabras clave: Construcción de instrumentos; habilidades sociales; comunicación alternativa. 
http://dx.doi.org/10.5902/1984686X42602

\section{Introdução}

Em âmbito internacional tem sido extensa a produção de pesquisas sobre habilidades sociais de pessoas com deficiência. Contudo, no Brasil, estes estudos são escassos, provavelmente, devido à carência de instrumentos de avaliação com o objetivo de atender demandas específicas desta população (CARMO, 2019; DEL PRETTE, Z; DEL PRETTE, 2004; QUITERIO; NUNES, 2018). Crianças e adolescentes com deficiência constituem-se como um grupo mais propenso a déficits nos comportamentos socialmente desejáveis, visto que as demandas sociais, em diferentes contextos, são constantes e fatores como a exclusão, o preconceito e a falta de recursos arquitetônicos e atitudinais adequados para inclusão dificultam o desenvolvimento satisfatório das habilidades sociais (LYONS et al., 2016).

No estudo das habilidades sociais, em grupos de pessoas com deficiência, faz-se necessário destacar aspectos como: caracterização do repertório de habilidades sociais, comparação deste repertório com população sem deficiência, verificação das habilidades preservadas e com déficits nesta população, estabelecimento de diretrizes para a promoção das habilidades, identificação de variáveis que possam afetar o desenvolvimento de tais habilidades e avaliação experimental dos efeitos dos programas de promoção das habilidades sociais (DEL PRETTE; DEL PRETTE, 2005a; FREITAS; DEL PRETTE, 2013). A avaliação multimodal, envolvendo a utilização de diferentes recursos, em diferentes ambientes e por meio de diferentes parceiros como pais, professores e colegas, tem sido enfatizada principalmente ao considerar-se o planejamento e a aplicação de programas de promoção de habilidades sociais de pessoas com deficiência (DEL PRETTE; DEL PRETTE, 2004; ROSIN-PINOLA; DEL PRETTE, 2014). Neste sentido, estes autores ressaltam que a educação inclusiva requer a elaboração de condições diferenciadas de ensino para que ocorra a aprendizagem. Elliott e Gresham (2008) apresentam instrumentos internacionais que atendem tanto aos alunos com como aos sem deficiência, mas é patente a necessidade de elaboração de instrumentos desenvolvidos em nossa realidade e não somente de instrumentos adaptados. Conforme a nota técnica do Conselho Federal de Psicologia (2013) a construção, adaptação e validação de instrumentos para pessoas com deficiência devem atentar para alguns aspectos específicos, tais como: (a) adaptação não se resume em alterar somente um aspecto do instrumento, mas em revisar os procedimentos de aplicação; (b) foco no construto teórico; (c) conhecimento do público, bem como atenção ao manuseio do instrumento e (d) pessoas com deficiencia devem avaliar o instrumento, 
http://dx.doi.org/10.5902/1984686X42602

especialmente em relação ao uso, acesso e clareza, bem como recomenda-se a consulta a especilistas da área.

As limitações físicas, sensoriais ou orgânicas, bem como o comportamento social diferenciado de pessoas com deficiências (intelectual, sensorial, física, transtornos do espectro do autismo) podem causar diferentes impactos no desenvolvimento do repertório de habilidades sociais e também no desempenho social, acarretando consequências nos aspectos acadêmicos e nas relações interpessoais. No contexto das relações interpessoais, um dos aspectos considerados fundamentais tanto na perpetuação como na promoção da superação das dificuldades da pessoa com necessidade educacional especial é a comunicação, visto que o ser humano, como destacam Hoff (2006) e Schirmer (2018), vivencia um constante processo comunicativo. As dificuldades de comunicação podem comprometer tanto a aquisição de sistemas simbólicos, como, por conseguinte, a cognição e o desenvolvimento das habilidades sociais (FREITAS; DEL PRETTE, 2013; QUITERIO; NUNES, 2017). Esta constitui-se como um constructo descritivo dos comportamentos sociais valorizados em determinada cultura com alta probabilidade de resultados favoráveis para o indivíduo, o grupo e a comunidade (DEL PRETTE; DEL PRETTE, 2017).

American Speech-Language-Hearing Association (ASHA) destaca que em cada duzentas pessoas uma é incapaz de comunicar-se por meio da fala, o que pode ser atribuído a fatores neurológicos, físicos, emocionais e cognitivos. Neste universo, estão presentes pessoas com paralisia cerebral. Esses indivíduos possuem um atraso de desenvolvimento neuropsicomotor, o qual implica em alterações no tônus muscular, na qualidade de movimento, nas percepções e na capacidade de apreender e interpretar os estímulos ambientais. Muitas vezes, as sequelas da paralisia cerebral tornam-se agravadas pelas dificuldades que essas pessoas apresentam em explorar o ambiente e em comunicarse com o mundo externo (GERALIS, 2007; NUNES, 2003; RIBEIRO; PORTO; VANDENBERGHE, 2013).

Sob a denominação de alunos com paralisia cerebral, encontram-se crianças com sintomatologias muito diferentes e de prognósticos muito variáveis. Pode-se encontrar desde crianças com perturbações motoras discretas, até crianças cuja alteração as impede de realizar, praticamente, qualquer movimento voluntário; desde crianças com uma inteligência mediana ou superior até crianças com uma deficiência intelectual extremamente grave, com ou sem distúrbios sensoriais associados (GERALIS, 2007; NUNES, 2003; RIBEIRO; PORTO; VANDENBERGHE, 2013). 
http://dx.doi.org/10.5902/1984686X42602

Estima-se que 65\% das pessoas com paralisia cerebral, além dos padrões atípicos de postura, movimento e tônus postural, apresentam também dificuldades de comunicação oral tanto em função de comprometimento do aparelho fono - articulatório (anartrias disartrias) - quanto ao nível cortical (apraxias e afasias) (NUNES, 2003). Tal dificuldade de comunicação pode estar associada: (a) alterações cognitivas (deficiência intelectual em diversos graus), (b) aspectos emocionais e (c) aspectos ambientais da falta de estimulação ou estimulação inadequada para a ocorrência de dificuldades de comunicação (QUITERIO; NUNES, 2017).

A Comunicação Alternativa (CA) constitui-se como uma área multidisciplinar da Tecnologia Assistiva, que envolve o emprego de diferentes recursos manuais, gráficos e tecnológicos que favoreçam a expressão e a comunicação de indivíduos sem fala articulada com seus interlocutores (BERSH, 2007; SCHIRMER, 2018). Neste sentido, a CA usa gestos manuais, expressões faciais e corporais. Utiliza ainda os símbolos gráficos, tanto os bidimensionais como fotografias, gravuras desenhos, linguagem alfabética, como os tridimensionais, incluindo-se aí, por exemplo, os objetos reais e miniaturas. Para efetuar a comunicação face a face utiliza voz digitalizada ou sintetizada. Apresenta dois propósitos tanto o de promover e suplementar a fala como o de oferecer uma forma alternativa, se para o sujeito for impossível desenvolver a fala (MASSARO; DELIBERATO, 2017).

Em parceria com seus interlocutores e por meio do uso dos sistemas de CA, o indivíduo sem fala articulada amplia sua competência comunicativa (QUITERIO; NUNES, 2017). Assim, pessoas com paralisia cerebral, sem fala articulada, poderiam desenvolver suas habilidades sociais por meio de recursos alternativos de comunicação ampliando a interação com seus interlocutores. Mas como avaliar tais habilidades nessa população?

A avaliação das habilidades sociais pode ser realizada por meio de: (a) observação do desempenho social contextual, (b) escalas de avaliação do comportamento, (c) entrevistas e outros procedimentos de avaliação sociométrica (DEL PRETTE; DEL PRETTE, 2017). Dentre estas diferentes modalidades de medida, destaca-se o uso de inventários, nos quais se registra a frequência de determinadas reações, preenchidas tanto por autorrelato, quanto por familiares ou professores (mais frequente na avaliação em crianças e adolescentes) (BORSA; SEIZE, 2018; CORDIER et al., 2015; PASQUALI, 1998).

Em âmbito internacional, Humphrey et al. (2011) realizaram um estudo de revisão de doze instrumentos de avaliação de habilidades sociais e emocionais de crianças e adolescentes. Posteriormente, Cordier et al. (2015), em um estudo de revisão, descreveram 
http://dx.doi.org/10.5902/1984686X42602

o público, o modelo teórico e os procedimentos dos 36 estudos e 9 manuais, publicados após o ano de 1994. Devido às qualidades psicométricas, Gresham (2016) destaca quatro instrumentos de avaliação das habilidades sociais: (i) Social Skills Improvement SystemRating Scales (SSIS-RS); (ii) Walker-McConnell Scale of Social Competence and School Adjustment (WMS); (iii) School Social Behavior Scales (SSBS-2); e (iv) Preschool and Kindergarten Behavior Scales (PKBS-2).

No contexto nacional, utilizou-se como base o Sistema de Avaliação de Testes Psicológicos (SATEPSI ${ }^{1}$ ) e cinco instrumentos destinam-se à avaliação das habilidades sociais de crianças e/ou adolescentes: (a) Sistema Multimídia de Habilidades Sociais de Crianças (SMHSC-Del-Prette) (DEL PRETTE; DEL PRETTE, 2005b), um sistema de avaliação que apresenta 21 vídeos de situações de interações sociais, no contexto escolar, em dois formatos: impresso e por meio de arquivos de multimídia. A criança escolhe uma reação dentre as três opções: habilidosa, não habilidosa ativa e não habilidosa passiva. 0 SMHSC possibilita, além da autoavaliação, a percepção avaliativa dos professores; (b) Inventário de Habilidades Sociais para Adolescentes (IHSA-Del-Prette) (DEL PRETTE; DEL PRETTE, 2009), uma escala de autorrelato, normatizada para jovens com idades entre 12 e 17 anos. O inventário é composto por 38 itens (pontuados em escala Likert de 5 pontos), agrupados em seis subclasses de Habilidades Sociais; (c) Roteiro de Entrevista de Habilidades Sociais Educativas Parentais (RE-HSE-P) (BOLSONI-SILVA; LOUREIRO; MARTURANO, 2011), um roteiro, composto de perguntas abertas e fechadas, de avaliação das Habilidades Sociais Educativas Parentais (HSE-P) por meio da entrevista semiestruturada. A entrevista deve ser gravada para posterior análise de acordo com as tabelas disponíveis no manual. É um instrumento efetivo para caracterizar as HSE-P e identificar problemas de comportamento em crianças. As categorias comportamentais são classificadas em clínico, limítrofe e não clínico; (d) Teste de Habilidades Sociais para Crianças em Situação Escolar (THAS-C) (BARTHOLOMEU; SILVA; MONTIEL, 2014), composto por 23 itens (escala Likert de 3 pontos) dispostos em três subcategorias de habilidades. O instrumento visa identificar a existência de déficits nas interações interpessoais, por meio da frequência com que a criança apresenta o comportamento descrito na situação; (e) Inventário de Habilidades Sociais, Problemas de Comportamento e Competência Acadêmica para Crianças (SSRS) (DEL PRETTE; FREITAS; BANDEIRA, 2016), um instrumento que envolve o autorrelato, bem como a avaliação de seus interlocutores, tais como familiares e professores. A escala (Likert de 3 pontos) de 
habilidades sociais preenchida pela própria criança conta com 20 itens. Os familiares preenchem as escalas relativas às habilidades sociais e aos problemas de comportamento. E os professores avaliam as habilidades sociais, a competência acadêmica e os problemas de comportamento que são divididos em três fatores: internalizantes, externalizantes e hiperatividade (o último, somente na escala para professores).

Contudo, não houve registro até o presente momento de elaboração/adaptação de nenhum instrumento destinado à população com deficiência, centrando-se alguns estudos (CARMO, 2019; FREITAS; DEL PRETTE, 2010, 2013) em aplicação dos inventários já existentes. Neste sentido, tornou-se ainda mais proeminente a elaboração de um recurso específico para uma parcela da população com dificuldades motoras e impossibilitada de emitir a oralidade para que se lhes pudesse oferecer a possibilidade de autopercepção de suas habilidades sociais e, com isto, auxiliar no planejamento das intervenções. Assim, este artigo apresenta a construção e avaliação do Inventário de Habilidades Sociais para Alunos Sem Fala Articulada (IHS-ASFA).

\section{Método}

\section{Participantes}

Os participantes eram alunos de uma Escola Especial, situada na Zona [OMITIDO] da cidade do [OMITIDO], conforme demonstra a Tabela 1. Essa escola tem como clientela crianças, adolescentes e jovens com deficiências físicas, auditivas, visuais, intelectuais, múltiplas ou Transtorno do Espectro Autista. A escola possui salas de aula, refeitório, pátio, sala de educação física, quadra, clube de mães, compreendendo os espaços frequentados pelos alunos. As sessões de aplicação dos instrumentos foram realizadas na própria escola à qual pertenciam os sujeitos participantes.

Tabela 1 - Caracterização dos participantes da pesquisa

\begin{tabular}{c|c|c|c|c|c|c}
\hline $\begin{array}{c}\text { NOME } \\
\text { FICTícIO }\end{array}$ & IDADE & SEXO & DIAGNÓSTICO & $\begin{array}{c}\text { TEMPO DE } \\
\text { ESCOLARIDADE }\end{array}$ & $\begin{array}{c}\text { FORMAS DE } \\
\text { COMUNICAÇÃO }\end{array}$ & $\begin{array}{c}\text { ESTUDO } \\
\text { EXPERI- } \\
\text { MENTAL }\end{array}$ \\
\hline Carolina & 12 & feminino & $\begin{array}{c}\text { Paralisia } \\
\text { cerebral }\end{array}$ & 7 anos & $\begin{array}{c}\text { Mista } \\
\text { (gestual e gráfica) }\end{array}$ & 2 \\
\hline Duda & 9 & feminino & $\begin{array}{c}\text { Paralisia } \\
\text { cerebral }\end{array}$ & 5 anos & $\begin{array}{c}\text { Mista } \\
\text { (gestual e gráfica) }\end{array}$ & 2 \\
\hline Fábio & 24 & masculino & $\begin{array}{l}\text { Paralisia } \\
\text { cerebral }\end{array}$ & 15 anos & $\begin{array}{c}\text { Mista } \\
\text { (gestual e gráfica) }\end{array}$ & 2 \\
\hline
\end{tabular}


http://dx.doi.org/10.5902/1984686X42602

Tabela 1 - Caracterização dos participantes da pesquisa

\begin{tabular}{c|c|c|c|c|c|c}
\hline $\begin{array}{c}\text { NOME } \\
\text { FICTícIO }\end{array}$ & IDADE & SEXO & DIAGNÓSTICO & $\begin{array}{c}\text { TEMPO DE } \\
\text { ESCOLARIDADE }\end{array}$ & $\begin{array}{c}\text { FORMAS DE } \\
\text { COMUNICAÇÃO }\end{array}$ & $\begin{array}{c}\text { ESTUDO } \\
\text { EXPERI- } \\
\text { MENTAL }\end{array}$ \\
\hline Ingrid & 24 & feminino & $\begin{array}{l}\text { Paralisia } \\
\text { cerebral }\end{array}$ & 15 anos & $\begin{array}{c}\text { Mista } \\
\text { (gestual e gráfica) }\end{array}$ & 2 \\
\hline Júlia & 21 & feminino & $\begin{array}{l}\text { Paralisia } \\
\text { cerebral }\end{array}$ & 14 anos & $\begin{array}{c}\text { Mista } \\
\text { (gestual e gráfica) }\end{array}$ & 1 \\
\hline Júlio & 14 & masculino & $\begin{array}{l}\text { Paralisia } \\
\text { cerebral }\end{array}$ & 9 anos & $\begin{array}{c}\text { Mista } \\
\text { (gestual e gráfica) }\end{array}$ & 2 \\
\hline Júnior & 9 & masculino & $\begin{array}{l}\text { Paralisia } \\
\text { cerebral }\end{array}$ & 4 anos & $\begin{array}{c}\text { Mista } \\
\text { (gestual e gráfica) }\end{array}$ & 2 \\
\hline Kendel & 9 & masculino & $\begin{array}{l}\text { Paralisia } \\
\text { cerebral }\end{array}$ & 5 anos & $\begin{array}{c}\text { Mista } \\
\text { (gestual e gráfica) }\end{array}$ & 2 \\
\hline Laura & 22 & feminino & $\begin{array}{l}\text { Paralisia } \\
\text { cerebral }\end{array}$ & 14 anos & $\begin{array}{c}\text { Mista } \\
\text { (gestual e gráfica) }\end{array}$ & 1 \\
\hline Regina & 10 & feminino & $\begin{array}{l}\text { Síndrome } \\
\text { Freeman }\end{array}$ & 6 anos & $\begin{array}{c}\text { Mista } \\
\text { (gestual e gráfica) }\end{array}$ & 2 \\
\hline Sandra & 18 & feminino & $\begin{array}{l}\text { Paralisia } \\
\text { cerebral }\end{array}$ & 4 anos & $\begin{array}{c}\text { Mista } \\
\text { (gestual e gráfica) }\end{array}$ & 1 \\
\hline Vitor & 23 & masculino & $\begin{array}{l}\text { Paralisia } \\
\text { cerebral }\end{array}$ & 15 anos & $\begin{array}{c}\text { Mista } \\
\text { (gestual e gráfica) }\end{array}$ & 1 \\
\hline
\end{tabular}

Fonte: arquivo pessoal da primeira autora (2009).

\section{Instrumentos}

Com base na proposta multimodal, foram utilizados os seguintes instrumentos de avaliação (DEL PRETTE; DEL PRETTE, 2005b; QUITERIO; GERK; NUNES, 2017): (a) protocolo de observação direta para registrar os comportamentos dos alunos em situação natural, bem como para categorizar os comportamentos não verbais; (b) entrevista semiestruturada, contendo 10 itens para coletar a percepção da professora sobre as habilidades sociais dos seus alunos; (c) questionário composto de 20 itens, com a finalidade de investigar como os familiares percebiam as relações interpessoais dos filhos, e (d) Inventário de Habilidades Sociais para Alunos Sem Fala Articulada (IHS-ASFA), contendo 20 situações geradoras de interações sociais, administrado aos alunos e às professoras de cada aluno. Devido ao objetivo do artigo, somente são apresentados os instrumentos (a) e (d) elaborados para esta pesquisa. 
http://dx.doi.org/10.5902/1984686X42602

\section{Procedimentos gerais}

O estudo foi aprovado pela Comissão de Ética em Pesquisa (COEP) da OMITIDO (parecer OMITIDO), bem como foi autorizado pela Secretaria Municipal de Educação da [OMITIDO] e pela direção da Unidade Escolar. Os familiares e as professoras dos participantes assinaram o Termo de Consentimento Livre e Esclarecido (TCLE).

\section{Procedimentos específicos}

A literatura apresenta diversos tipos de inventários específicos, aplicados a diferentes grupos, como crianças, adolescentes, adultos, idosos, casais (DEL PRETTE; DEL PRETTE, 2017), mas indica que a área voltada para pessoas com deficiência necessita de mais investimentos (DEL PRETTE; DEL PRETTE, 2004; QUITERIO; NUNES, 2017). Tendo como base o Sistema Multimídia de Avaliação de Habilidades Sociais (SMHSC) (DEL PRETTE; DEL PRETTE, 2005b), a Escala de Assertividade (ALVES, 2003) e as situações das observações diretas da avaliação multimodal, foi elaborado o Inventário de Habilidades Sociais para Alunos Sem Fala Articulada (IHS-ASFA), contendo a descrição de situações vivenciadas por alunos sem fala articulada na escola, tendo sido feitas adaptações quanto ao conteúdo, faixa etária e à apresentação (pranchas).

\section{1a Etapa: Construção dos itens do Instrumento.}

Com a definição do construto e a constatação da necessidade do desenvolvimento do inventário, bem como a delimitação da população-alvo passou-se à elaboração dos itens do instrumento (BORZA, SEIZE, 2018). O primeiro procedimento foi empregar a técnica de registro contínuo de observação ao vivo dos comportamentos dos alunos e das situações naturais de convívio escolar/social em cinco sessões com trinta minutos de duração em diferentes espaços como sala de aula, pátio, educação física e refeitório. Um protocolo foi utilizado para categorizar os componentes não verbais das interações, tendo como base o sistema de categorias proposto por Caballo (2003), bem como foi igualmente utilizado para descrever o repertório livre de habilidades sociais e adequar às situações propostas pelo inventário à realidade de alunos com deficiência e sem fala articulada.

Com este procedimento de adequação das situações geradoras para o IHS-ASFA procurou-se alcançar eficiência, efetividade e coerência na elaboração desse instrumento. Por exemplo, na aula de Educação Física, Laura e Heloísa formam uma dupla no tênis de mesa adaptado. Laura queria que Heloísa jogasse direito com ela, isto é, que tivesse 
http://dx.doi.org/10.5902/1984686X42602

atenção para rebater as bolas jogadas por Henrique. Contudo, Heloísa continuava sem prestar atenção e Laura acaba dando um empurrão e um grito com Heloísa que acaba afastando-se da mesa de ping-pong e, consequentemente, da atividade (relatório de registro de observação). Tais registros de observação possibilitaram a compreensão de resposta dos sujeitos participantes do primeiro estudo experimental, bem como a seleção de situações observadas no cotidiano escolar, as quais contribuíram para a construção do inventário.

Em seguida, essas situações oriundas do registro contínuo de observação ao vivo foram planificadas juntamente com as situações propostas por outros dois instrumentos que serviram de base para a elaboração dos itens do inventário. Cada uma das vinte situações do IHS-ASFA foi inspirada em diferentes fontes que estão indicadas na Tabela 2. As fontes podiam ser: (i) situações do registro contínuo dos alunos no ambiente escolar (instrumento "a"), (ii) Escala de Assertividade (ALVES, 2003) e (iii) SMHSC-Del-Prette (DEL PRETTE; DEL PRETTE, 2005b).

Tabela 2 - Fonte dos itens que compõem o IHS-ASFA

\begin{tabular}{|c|c|c|}
\hline SITUAÇÃO & $\begin{array}{c}\text { FONTE (RELATÓRIO DE } \\
\text { OBSERVAÇÃO / ESCALA DE } \\
\text { ASSERTIVIDADE OU SMHSC) }\end{array}$ & $\begin{array}{c}\text { ITEM DO PRESENTE } \\
\text { INSTRUMENTO - IHS-ASFA }\end{array}$ \\
\hline 1 & $\begin{array}{c}\text { Situação } 1 \text { do SMHSC - "Marina olha um } \\
\text { grupo de colegas jogando amarelinha e } \\
\text { está com muita vontade de brincar com } \\
\text { elas. O que Marina vai fazer?" }\end{array}$ & $\begin{array}{l}\text { "Laura olha para um grupo de } \\
\text { colegas jogando um jogo da } \\
\text { memória adaptado e gostaria de } \\
\text { jogar com elas. O que Laura vai } \\
\text { fazer?" }\end{array}$ \\
\hline 2 & $\begin{array}{l}\text { Situação } 9 \text { do SMHSC - “Júlio quer ver o } \\
\text { álbum de Raul, mas este não quer } \\
\text { mostrar. O que será que Júlio vai fazer?" }\end{array}$ & $\begin{array}{l}\text { "Henrique quer a prancha de } \\
\text { comunicação de Heloísa } \\
\text { emprestada, mas esta não } \\
\text { quer emprestar. O que } \\
\text { Henrique vai fazer?" }\end{array}$ \\
\hline 3 & $\begin{array}{c}\text { Questão } 3 \text { da Escala de Assertividade - } \\
\text { "Você está na fila da cantina do colégio, } \\
\text { e um garoto fura a fila na sua frente. O } \\
\text { que você faz?" }\end{array}$ & $\begin{array}{l}\text { "Laura está na fila da merenda } \\
\text { no refeitório. Ao chegar sua } \\
\text { vez, uma colega da outra turma } \\
\text { entra na sua frente. O que } \\
\text { Laura vai fazer?" }\end{array}$ \\
\hline 4 & $\begin{array}{c}\text { Item de exemplo da Escala de } \\
\text { Assertividade - "Você empresta o seu } \\
\text { caderno a um colega que quer copiar } \\
\text { uma matéria que perdeu. Depois ele lhe } \\
\text { devolve o caderno, porém com algumas } \\
\text { folhas enrugadas e sujas de suco que ele } \\
\text { deixou entornar. O que você faz?" }\end{array}$ & $\begin{array}{l}\text { “Júlia empresta sua prancha de } \\
\text { comunicação para Sandra, pois } \\
\text { ela esqueceu a dela em casa. } \\
\text { Depois, Sandra devolve a } \\
\text { prancha amassada e suja de } \\
\text { iogurte em alguns símbolos. O } \\
\text { que Júlia vai fazer?" }\end{array}$ \\
\hline
\end{tabular}


Tabela 2 - Fonte dos itens que compõem o IHS-ASFA

\begin{tabular}{|c|c|c|}
\hline SITUAÇÃO & $\begin{array}{c}\text { FONTE (RELATÓRIO DE } \\
\text { OBSERVAÇÃO / ESCALA DE } \\
\text { ASSERTIVIDADE OU SMHSC) }\end{array}$ & $\begin{array}{c}\text { ITEM DO PRESENTE } \\
\text { INSTRUMENTO - IHS-ASFA }\end{array}$ \\
\hline 5 & $\begin{array}{l}\text { Questão } 4 \text { da Escala de Assertividade } \\
\text { - "você está no play com seus amigos } \\
\text { e propõe um jogo, mas seus amigos } \\
\text { não gostam da ideia e propõem uma } \\
\text { outra brincadeira, que você até gosta } \\
\text { mas não era o que você queria } \\
\text { naquele momento. O que você faz?" }\end{array}$ & $\begin{array}{c}\text { "Henrique, Laura e Heloísa } \\
\text { estão na aula de Educação } \\
\text { Física e Laura propõe o jogo } \\
\text { de tênis de mesa adaptado, } \\
\text { mas Henrique e Heloísa não } \\
\text { concordam com a ideia e } \\
\text { querem jogar o arremesso de } \\
\text { saco de areia, mas Laura não } \\
\text { gosta desta brincadeira. O que } \\
\text { Laura vai fazer?" }\end{array}$ \\
\hline 6 & $\begin{array}{l}\text { Relatório de observação - "os alunos } \\
\text { foram vários dias assistir aos Jogos. } \\
\text { Como os Jogos Paraolímpicos não } \\
\text { vendiam ingressos era a ordem de } \\
\text { chegada que dava acesso aos estádios. } \\
\text { Houve um dia que os alunos não } \\
\text { conseguiram entrar, então, a prof. Clara } \\
\text { sugeriu que os alunos fizessem um } \\
\text { passeio de trem pela cidade". }\end{array}$ & $\begin{array}{l}\text { "Thiago junto com sua turma foi } \\
\text { para o PARAPAN assistir o } \\
\text { basquete de cadeira de rodas. } \\
\text { Mas ao chegar ao estádio, os } \\
\text { ingressos já haviam se } \\
\text { esgotado e então, a professora } \\
\text { propõe que eles desistam e } \\
\text { vão fazer outro passeio. O que } \\
\text { Thiago vai fazer?" }\end{array}$ \\
\hline 7 & $\begin{array}{l}\text { Relatório de observação - "Laura e } \\
\text { Heloísa formaram uma dupla no tênis de } \\
\text { mesa adaptado. Laura queria que } \\
\text { Heloísa jogasse direito com ela, isto é, } \\
\text { que tivesse atenção para rebater as } \\
\text { bolas jogadas por Henrique. Contudo, } \\
\text { Heloísa continuava sem prestar atenção } \\
\text { e Laura acabou dando um empurrão e } \\
\text { um grito com Heloísa que acabou se } \\
\text { afastando da mesa de ping-pong e, } \\
\text { desistindo de continuar no jogo". }\end{array}$ & $\begin{array}{l}\text { "Na aula de Educação Física, } \\
\text { Laura, Heloísa e Henrique estão } \\
\text { jogando tênis de mesa adaptado. } \\
\text { Mas Heloísa não presta atenção e } \\
\text { faz com que sua dupla (ela e } \\
\text { Laura) esteja perdendo a partida. } \\
\text { O que Laura vai fazer?" }\end{array}$ \\
\hline 8 & $\begin{array}{c}\text { Questão } 9 \text { da Escala de Assertividade - } \\
\text { "um colega seu de subclasse está } \\
\text { incomodando muito a aula, você e a } \\
\text { turma toda, com brincadeiras. O que } \\
\text { você faz?" }\end{array}$ & $\begin{array}{l}\text { "Na sala de aula, Henrique } \\
\text { quer colocar o som muito alto e } \\
\text { não dá para os colegas } \\
\text { entenderem a professora. Júlia } \\
\text { pede para Henrique abaixar o } \\
\text { som, mas ele não concorda. O } \\
\text { que Júlia vai fazer?" }\end{array}$ \\
\hline 9 & $\begin{array}{l}\text { Relatório de observação - Atividade em } \\
\text { sala de aula: levantamento de } \\
\text { vocabulário para montagem de pranchas } \\
\text { de CAA. "A professora estava fazendo o } \\
\text { levantamento de vocabulário com a aluna } \\
\text { Duda havia poucos minutos e a outra } \\
\text { aluna começou a reclamar direcionando- } \\
\text { se até o computador". }\end{array}$ & $\begin{array}{l}\text { "Sandra está usando o } \\
\text { computador na sala de aula } \\
\text { somente há quinze minutos e } \\
\text { Heloísa também quer usar o } \\
\text { computador. O que Sandra vai } \\
\text { fazer?" }\end{array}$ \\
\hline 10 & $\begin{array}{c}\text { Questão } 5 \text { da Escala de Assertividade - } \\
\text { "Se você continua dúvidas numa } \\
\text { determinada matéria, mesmo o professor } \\
\text { já tendo explicado longamente. O que } \\
\text { você faz?" }\end{array}$ & $\begin{array}{l}\text { “Laura está prestando atenção } \\
\text { na aula, mas não está } \\
\text { entendendo a explicação da } \\
\text { professora Clara sobre as } \\
\text { pranchas com os verbos. O } \\
\text { que Laura vai fazer?” }\end{array}$ \\
\hline
\end{tabular}


Tabela 2 - Fonte dos itens que compõem o IHS-ASFA

\begin{tabular}{|c|c|c|}
\hline SITUAÇÃO & $\begin{array}{c}\text { FONTE (RELATÓRIO DE } \\
\text { OBSERVACCÃO / ESCALA DE } \\
\text { ASSERTIVIDADE OU SMHSC) }\end{array}$ & $\begin{array}{c}\text { ITEM DO PRESENTE } \\
\text { INSTRUMENTO - IHS-ASFA }\end{array}$ \\
\hline 11 & $\begin{array}{l}\text { Relatório de observação - "Os alunos } \\
\text { estavam com vários cartões organizados } \\
\text { perto de si para montar o painel síntese } \\
\text { com os ingredientes e modo de preparo } \\
\text { da caixa com material reciclado. A aluna } \\
\text { Heloísa em algum momento quis pegar } \\
\text { símbolos de Laura e esta não aceitou } \\
\text { que Heloísa mexesse em seu arquivo de } \\
\text { cartões". }\end{array}$ & $\begin{array}{c}\text { “Henrique está sentado ao lado } \\
\text { da Júlia e está puxando seu } \\
\text { álbum de fotografias. Júlia já } \\
\text { pediu para ele parar, mas } \\
\text { Henrique continua mexendo no } \\
\text { seu álbum. O que Júlia vai } \\
\text { fazer?” }\end{array}$ \\
\hline 12 & $\begin{array}{l}\text { Questão } 13 \text { da Escala de Assertividade - } \\
\text { "seu colega de sala mostra pra você o } \\
\text { trabalho de escola que ele fez, e diz que } \\
\text { o trabalho dele está muito mais bonito } \\
\text { que o seu. O que você faz?" }\end{array}$ & $\begin{array}{l}\text { “Thiago fez uma prancha de } \\
\text { comunicação da categoria } \\
\text { esportes e mostra para Sandra } \\
\text { sinalizando que o dele está } \\
\text { mais bonito do que o dela. O } \\
\text { que Sandra vai fazer?” }\end{array}$ \\
\hline 13 & $\begin{array}{l}\text { Relatório de observação - Momento de } \\
\text { merenda dos alunos da Instituição } \\
\text { Escolar. "Todos os alunos estavam } \\
\text { sentados à mesa com sua professora. A } \\
\text { tia da aluna Sandra todos os dias a } \\
\text { levava para lanchar no pátio da escola, } \\
\text { perto de algumas mães. Percebia-se que } \\
\text { o olhar de Sandra neste momento era de } \\
\text { tristeza". }\end{array}$ & $\begin{array}{l}\text { "Na hora do recreio, Laura e } \\
\text { Heloísa lancham no refeitório. Elas } \\
\text { chamam Sandra para lanchar com } \\
\text { elas. Na mesma hora, a tia de } \\
\text { Sandra a chama para lanchar no } \\
\text { pátio. O que Sandra vai fazer?" }\end{array}$ \\
\hline 14 & $\begin{array}{l}\text { Relatório de observação - Atividade: } \\
\text { retomar o projeto da turma sobre artes e } \\
\text { material reciclado. "Os alunos estavam } \\
\text { sentados em círculo e a professora } \\
\text { estava apresentando os cartões. } \\
\text { Percebeu-se que alguns alunos } \\
\text { entendiam os cartões com símbolos e } \\
\text { outros alunos não estavam entendo a } \\
\text { proposta". \& situação } 4 \text { do SMHSC - } \\
\text { "Pedro presta atenção à aula, mas não } \\
\text { consegue entender a lição. Ele percebe } \\
\text { que o colega Cássio está entendendo. O } \\
\text { que Pedro vai fazer?" }\end{array}$ & $\begin{array}{l}\text { "Na sala de aula, a turma está } \\
\text { construindo um prato de material } \\
\text { reciclado. A professora Clara está } \\
\text { utilizando os cartazes de CAA com } \\
\text { os símbolos dos materiais e das } \\
\text { etapas do trabalho. Júlia não } \\
\text { entendeu um símbolo da atividade } \\
\text { e percebeu que Henrique está } \\
\text { entendendo os símbolos. O que } \\
\text { Júlia vai fazer?" }\end{array}$ \\
\hline 15 & $\begin{array}{l}\text { Situação } 13 \text { do SMHSC - "O professor } \\
\text { pede sugestões para a festinha do dia } \\
\text { das crianças. Camila tem uma ideia. O } \\
\text { que será que Camila vai fazer?" }\end{array}$ & $\begin{array}{l}\text { "A professora Clara está com } \\
\text { cartões em branco na mão } \\
\text { para o grupo dar sugestões } \\
\text { para a Festa do Dia das } \\
\text { Crianças. Heloísa tem uma } \\
\text { ideia para a festa. O que } \\
\text { Heloísa vai fazer?" }\end{array}$ \\
\hline 16 & $\begin{array}{c}\text { Relatório de observação - Atividade: a } \\
\text { professora trouxe cartões com imagens } \\
\text { de esportes e letras em caixa altas para } \\
\text { os alunos montarem as palavras sobre } \\
\text { os esportes correspondentes. Cada } \\
\text { aluno teve que montar três palavras - } \\
\text { esportes. A professora dava pistas sobre } \\
\text { os esportes. }\end{array}$ & $\begin{array}{l}\text { "A professora Clara está } \\
\text { elaborando com o grupo mais } \\
\text { uma receita com material } \\
\text { reciclado. A professora pediu } \\
\text { para Henrique escrever } \\
\text { algumas palavras. O que } \\
\text { Henrique vai fazer?" }\end{array}$ \\
\hline
\end{tabular}


Tabela 2 - Fonte dos itens que compõem o IHS-ASFA

\begin{tabular}{|c|c|c|}
\hline SITUAÇÃO & $\begin{array}{c}\text { FONTE (RELATÓRIO DE } \\
\text { OBSERVAÇÃO / ESCALA DE } \\
\text { ASSERTIVIDADE OU SMHSC) }\end{array}$ & $\begin{array}{c}\text { ITEM DO PRESENTE } \\
\text { INSTRUMENTO - IHS-ASFA }\end{array}$ \\
\hline 17 & $\begin{array}{c}\text { Situação } 3 \text { do SMHSC - "José pede para } \\
\text { ver a caneta nova de Ana e a deixa cair. } \\
\text { A caneta se estraga e Ana fica muito } \\
\text { triste. O que Ana vai fazer?" }\end{array}$ & $\begin{array}{l}\text { "Heloísa pede para ver o } \\
\text { comunicador de Thiago. } \\
\text { Heloísa deixa cair e estraga o } \\
\text { comunicador. Thiago fica triste. } \\
\text { O que Thiago vai fazer?" }\end{array}$ \\
\hline 18 & $\begin{array}{l}\text { Relatório de observação - Atividade: os } \\
\text { alunos da escola estavam participando } \\
\text { dos Jogos inclusivos em diferentes } \\
\text { modalidades e em diferentes níveis. } \\
\text { Observação: Havia alunos com familiares } \\
\text { presentes e outros somente com as } \\
\text { professoras, o que acarretou em torcida } \\
\text { mais forte para alguns alunos do que } \\
\text { para outros \& situação } 7 \text { do SMHSC - } \\
\text { "Rodrigo e Felipe estão brincando de } \\
\text { queda de braço. Todos estão torcendo } \\
\text { para Felipe, mas ele acaba perdendo. O } \\
\text { que Felipe vai fazer?" }\end{array}$ & $\begin{array}{c}\text { "Júlia e Laura estão brincando } \\
\text { de arremesso da bola de meia. } \\
\text { O grupo está torcendo para } \\
\text { Laura, mas ela acaba } \\
\text { perdendo. O que Laura vai } \\
\text { fazer?" }\end{array}$ \\
\hline 19 & $\begin{array}{c}\text { Situação } 10 \text { do SMHSC - "Cistina está } \\
\text { com o pé quebrado e tem dificuldades } \\
\text { para subir a escada. Seu colega Alfredo } \\
\text { está passando. O que será que ele vai } \\
\text { fazer?" }\end{array}$ & $\begin{array}{l}\text { "Laura está com dificuldade } \\
\text { para empurrar a cadeira de } \\
\text { rodas na rampa. Henrique está } \\
\text { passando pela rampa. O que } \\
\text { Henrique vai fazer?" }\end{array}$ \\
\hline 20 & $\begin{array}{l}\text { Questão } 14 \text { da Escala de Assertividade - } \\
\text { "os pais de seu amigo convidaram você } \\
\text { para passar o dia brincando na casa } \\
\text { deles e ficar para dormir também. Seus } \\
\text { pais deixam você passar o dia, mas não } \\
\text { deixam você dormir lá. O que você faz?" }\end{array}$ & $\begin{array}{l}\text { "Sandra vai passar o final de } \\
\text { semana na casa de praia. Sandra } \\
\text { mostra na prancha de } \\
\text { comunicação para Júlia os } \\
\text { símbolos - sol e casa de praia e a } \\
\text { convida para ir à sua casa. O que } \\
\text { Júlia vai fazer?" }\end{array}$ \\
\hline
\end{tabular}

Fonte: arquivo pessoal da primeira autora (2009).

Mediante essa análise, foi elaborado o IHS-ASFA, composto por 20 itens de múltipla escolha, que pretendeu avaliar seis subclasses de habilidades sociais. Cada item representa uma subclasse de habilidades sociais e apresenta uma situação de interação social seguida por três alternativas de reação (comportamento social): desejável; indesejável ativo; indesejável passivo. A Tabela 3 apresenta a distribuição dos itens, incluindo as subclasses das habilidades sociais, bem como as habilidades envolvidas, os interlocutores e os contextos. Aspectos a sinalizar: (a) as subclasses e a distribuição dos itens seguiram a taxonomia proposta por Del Prette e Del Prette (2005a) e (b) as subclasses empatia e civilidade aparecem juntas, seguindo o modelo do SMHSC (DEL PRETTE, Z.; DEL PRETTE, 2005b). Estudos indicam que a avaliação de um construto pode ser medida com uma quantidade de 20 itens (PASQUALI, 1998). 
Tabela 3 - Distribuição dos itens do IHS-ASFA

\begin{tabular}{|c|c|c|c|c|}
\hline SUBESCALAS & ITEM & HABILIDADES & INTERLOCUTOR & CONTEXTO \\
\hline Fazer amizades & 1 & $\begin{array}{c}\text { Juntar-se a um grupo em } \\
\text { brincadeiras }\end{array}$ & Grupo & Sala de aula \\
\hline Autocontrole & 2 & Negociar, convencer & Colega & Sala de aula \\
\hline Assertividade & 3 & $\begin{array}{l}\text { Pedir mudança de } \\
\text { comportamento }\end{array}$ & Colega & Recreio \\
\hline Assertividade & 4 & Expressar desagrado & Colega & Sala de aula \\
\hline Assertividade & 5 & Propor nova brincadeira & Grupo & Aula de E.F. \\
\hline $\begin{array}{c}\text { Solução de Problemas } \\
\text { Interpessoais }\end{array}$ & 6 & Perguntar/questionar & Grupo / prof. & Aula-passeio \\
\hline Autocontrole & 7 & Demonstrar espírito esportivo & Grupo & Aula de E.F. \\
\hline $\begin{array}{c}\text { Solução de Problemas } \\
\text { Interpessoais }\end{array}$ & 8 & Mediar conflito entre colegas & Grupo & Sala de aula \\
\hline Autocontrole & 9 & Recusar pedido de colega & Colega & Sala de aula \\
\hline Empatia e civilidade & 10 & Fazer pergunta à professora & Professor & Sala de aula \\
\hline Assertividade & 11 & Resistir à pressão do colega & Colega & Sala de aula \\
\hline Empatia e civilidade & 12 & Elogiar a produção do colega & Colega & Sala de aula \\
\hline Fazer amizades & 13 & Aceitar um convite & Colegas & Recreio \\
\hline $\begin{array}{l}\text { Habilidades Sociais } \\
\text { Acadêmicas }\end{array}$ & 14 & Pedir ajuda ao colega de classe & Colega & Sala de aula \\
\hline Empatia e civilidade & 15 & $\begin{array}{l}\text { Responder à pergunta da } \\
\text { professora }\end{array}$ & Professor & Sala de aula \\
\hline $\begin{array}{l}\text { Habilidades Sociais } \\
\text { Acadêmicas }\end{array}$ & 16 & $\begin{array}{c}\text { Lidar com as dificuldades } \\
\text { escolares }\end{array}$ & Colega & Sala de aula \\
\hline $\begin{array}{l}\text { Solução de Problemas } \\
\text { Interpessoais }\end{array}$ & 17 & $\begin{array}{c}\text { Buscar solução para os } \\
\text { problemas }\end{array}$ & Colega & Sala de aula \\
\hline Autocontrole & 18 & Demonstrar espírito esportivo & Colega & Aula de E.F. \\
\hline Empatia e civilidade & 19 & Oferecer ajuda & Colega & Pátio \\
\hline Fazer amizades & 20 & Fazer e aceitar convite & Colega & Passeio \\
\hline
\end{tabular}

Fonte: primeira autora, seguindo a base do SMHSC (DEL PRETTE; DEL PRETTE, 2005b).

Os itens presentes no IHS-ASFA retratam várias situações que abarcam o contexto escolar de alunos com deficiência e sem fala articulada, em suas interações com pares e profissionais de educação e em diferentes espaços escolares. O instrumento não esgota as possibilidades, mas permite a elaboração de uma amostra de habilidades importantes no relacionamento interpessoal, por meio das subclasses de habilidades sociais (DEL PRETTE; DEL PRETTE, 2005b), como (a) autocontrole - expressão dos sentimentos positivos e negativos, bem como influencia na manutenção dos relacionamentos; (b) empatia e civilidade - facilita nos relacionamentos, auxilia na comunicação e inclui habilidades de solidariedade; (c) assertividade - envolve a expressão apropriada de sentimentos, desejos e opiniões; (d) fazer amizades - favorece um contexto de reciprocidade, cooperação e manejo de conflitos, (e) solução de problemas interpessoais desenvolve a habilidade de identificar uma situação-problema, analisar possíveis 
http://dx.doi.org/10.5902/1984686X42602

alternativas para a solução e avaliar o processo de tomada de decisão; (f) habilidades sociais acadêmicas - envolvimento com a atividade escolar, seguir regras e comandos orais; fazer e responder perguntas (DEL PRETTE; DEL PRETTE, 2005a; QUITERIO, NUNES, 2018).

O referido instrumento passou pelo julgamento de dez pesquisadores ou profissionais na área de Educação Especial/Inclusiva, a saber: uma professora titular do Programa de Pós-Graduação em Educação, uma pós-doutoranda e duas doutorandas em Educação Especial, três pedagogas, uma terapeuta ocupacional e uma psicóloga e professora de classe especial na rede pública de ensino. Dos 20 itens do inventário, 19 apresentaram índice de concordância de 100\% e um de 90\%. Deste modo, não foram feitas alterações após a análise da pertinência dos itens e foi considerado um instrumento viável de aplicação para esta população. As situações 5, 7 e 18, referentes ao contexto da aula de Educação Física, foram também apresentadas à professora responsável que aprovou as situações, considerando-as condizentes com a práxis da instituição escolar. Após esta avaliação, foram elaborados o Protocolo e o Crivo de Respostas do IHS-ASFA.

O presente instrumento representou uma adaptação também no que diz respeito à apresentação, visto que se fez necessário atentar para as dificuldades motoras dos alunosalvo. Assim, para responder os itens, o aluno teve como opções: apontar para a figura ou sinalizar a figura-resposta a partir da varredura efetuada pela pesquisadora. A técnica de varredura exige que o indivíduo tenha uma resposta voluntária consistente, como piscar os olhos, sacudir a cabeça, sorrir ou emitir um som, sinalizando sua resposta (QUITERIO; NUNES, 2018).

As 20 cenas foram desenhadas por um profissional de comunicação (web design) e as imagens foram baseadas nas atividades propostas por Gutstein e Sheely (2002). Optouse por não colocar as expressões faciais nas pessoas desenhadas nas pranchas para não influenciar na escolha da reação, por exemplo, na reação 3 da Figura 1 (comportamento indesejável ativo), ao ver a expressão facial da emoção raiva - o participante poderia escolher outra opção socialmente esperada.

As cenas foram colocadas em uma prancha que se dividia em quatro partes: na dobra à direita havia o relato da situação, de modo que facilitasse a leitura para o examinador e, em seguida, voltando para posição horizontal, ficavam expostas as três possibilidades de reações para aquela situação. Cada prancha tinha a extensão de 19 centímetros, de modo a permitir tanto o gesto de apontar pelo sujeito, como a realização da varredura pela 
pesquisadora, para acompanhar a leitura da situação, conforme mostra o Quadro 1. A dimensão das pranchas foi baseada na Escala de Maturidade Mental Columbia (BURGEMEISTER; BLUM; LORGE, 2001), um instrumento de avaliação psicológica utilizado com pessoas que apresentam dificuldades motoras, conforme ilustra a Figura 1.

Figura 1 - Exemplo da apresentação do item 7 do IHS-ASFA

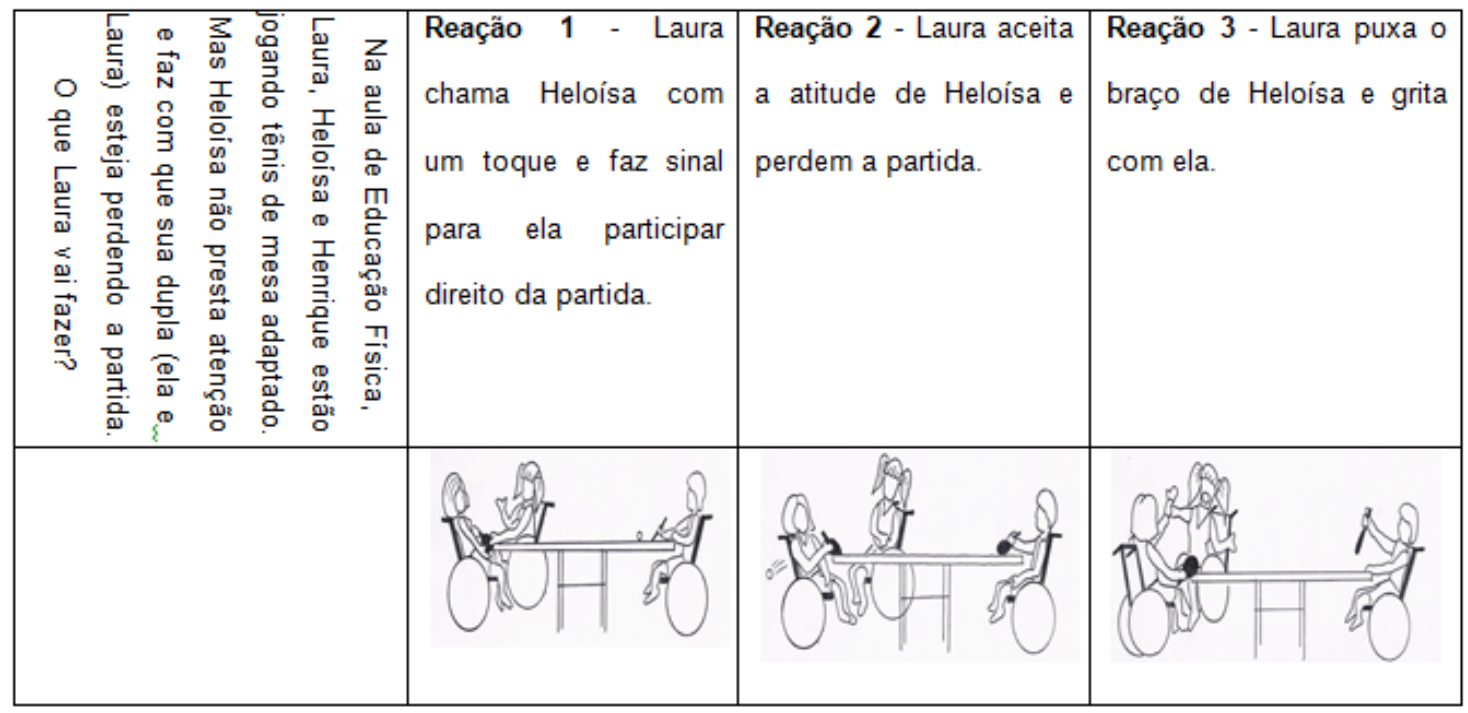

Fonte: arquivo pessoal da primeira autora (2009).

Em cada item, a criança foi solicitada a indicar a frequência com que apresentava cada reação. As opções de resposta para a frequência foram apresentadas sob a forma de cartões independentes. As opções basearam-se na escala Likert (COHEN; SWERDLIK; STURMAN, 2014): 1 - nunca; 2 - poucas vezes; 3 - às vezes; 4 - muitas vezes e 5 sempre. Para melhor compreensão dos participantes, acrescentaram-se pontos representando as quantidades, assim: nunca - cartão em branco; poucas vezes-poucas bolinhas e assim por diante. Cada aluno, de acordo com a funcionalidade motora e visual, tinha uma disposição de cartões sobre a mesa. Por exemplo, para alguns alunos era necessário colocar os cartões em disposição horizontal, um ao lado do outro; outros já poderiam trabalhar com os cartões dispostos tanto horizontalmente quanto verticalmente. Uma caixa azul continha as pranchas do Inventário. As pranchas ficaram dispostas em sequência em uma base com encaixes feita de papel cartão. A representação das opções de respostas está exibida na Figura 2. O mesmo procedimento de aplicação (frequência para cada reação do item) foi aplicado à professora de cada aluno. 
http://dx.doi.org/10.5902/1984686X42602

Figura 2 - Caixa do IHS-ASFA com os cartões das opções de frequência para cada reação

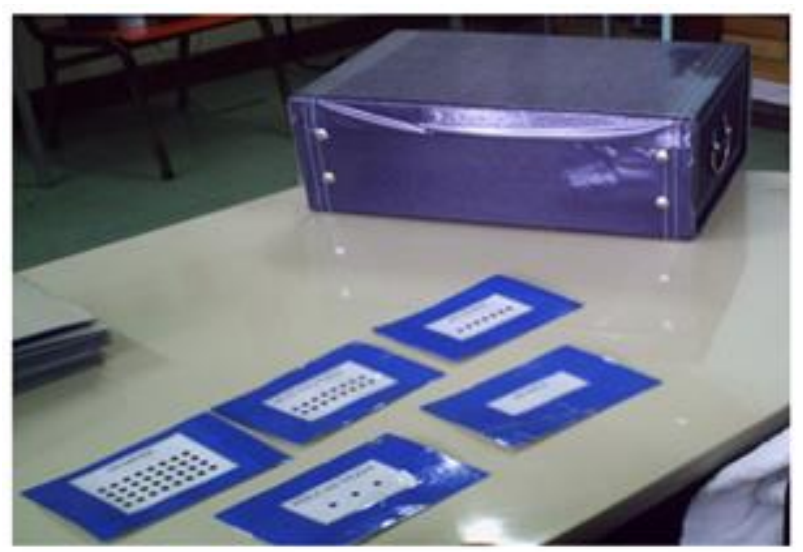

Fonte: arquivo pessoal da primeira autora (2009).

\section{2ª Etapa: Primeira aplicação experimental.}

O IHS-ASFA foi aplicado em quatro alunos que apresentavam paralisia cerebral, sem fala articulada, conforme Tabela 1 (indicados na coluna Estudo 1), os quais faziam uso sistemático ou não de recursos da comunicação alternativa. Durante a aplicação, fez-se necessário observar as peculiaridades de cada participante: duas participantes (Laura e Sandra) apontaram com facilidade os cartões com a frequência das respostas de cada reação, para Júlia foi necessário prender os cartões com fita crepe sobre a mesa e para Vitor foi necessário alterar a disposição dos cartões sobre a mesa devido ao campo visual.

As respostas eram anotadas no protocolo do inventário, bem como o tempo de execução. A seguir, cada resposta era classificada em Comportamento Desejável (CD emissão de comportamentos entre os dois extremos anteriores, na qual a pessoa emite uma reação coerente à demanda e à expectativa social), Comportamento Indesejável Passivo (CIP - pessoa se expressa de modo encoberto na interação social, através de mágoas, ressentimentos, ansiedade e esquiva) e Comportamento Indesejável Ativo (CIA sujeito expressa suas reações de modo aberto, com agressividade, autoritarismo, coerção, ironia ou de forma negativista) (DEL PRETTE; DEL PRETTE, 2017; DEL PRETTE; DEL PRETTE, 2005a). A classificação foi anotada no próprio Protocolo de Respostas, seguindo a classificação do Crivo de Respostas.

\section{Análise de dados ${ }^{2}$}

Para avaliar o grau de fidedignidade dos componentes não verbais desta etapa inicial da pesquisa com o primeiro grupo experimental, duas assistentes de pesquisa, que atuam 
com alunos com deficiência (fonoaudiologia e pedagogia), analisaram e categorizaram as sessões de observação. No preparo das observadoras, foi discutida cada forma de emissão do comportamento não verbal, com vistas a equalizar as observações e análises. Os protocolos de registro das assistentes e o da pesquisadora foram comparados pelo cálculo de acordos e desacordos. A porcentagem média de acordos referentes a todos os comportamentos observados foi de $85 \%$ (variação: $72 \%$ - 100\%), revelando um índice adequado de fidedignidade das categorizações (FAGUNDES, 1985).

Os dados do IHS-ASFA aplicado aos quatro alunos foram quantificados em termos de frequência, isto é, por meio da estatística descritiva, calculando-se a porcentagem da emissão de reações desejáveis e não desejáveis (passivas ou ativas), bem como da frequência (alta, parcial, baixa) de cada subclasse de habilidades sociais. Como o número de itens de observação não é igual para cada uma das subclasses de habilidades sociais, foi preparada uma tabela de equivalência com o intervalo de possibilidade de respostas de cada participante. Após esta classificação, procedeu-se com a ordenação estatística, a partir da seguinte fórmula: $\mathrm{X} \%=\mathrm{N}_{\mathrm{NHA}} * 100 /$ Total de itens do inventário (20). $\mathrm{O}$ mesmo procedimento foi realizado para as reações desejáveis e não desejáveis passivas.

Em busca de uma pesquisa consistente e visando eliminar as falhas de um estudo, optou-se por realizar a aplicação do IHS-ASFA junto à professora dos alunos participantes do estudo. A instrução dada à professora foi que respondesse considerando como cada aluno responderia aquele item.

$3^{\underline{a}}$ etapa: Análise da versão preliminar e da aplicação da primeira aplicação experimental.

Depois da avaliação da aplicação experimental, foram realizadas as alterações necessárias no IHS-ASFA. Em relação à funcionalidade do inventário, observou-se que o entendimento das situações possibilitou que as respostas fossem consideradas válidas, tendo sido possível classificá-las em comportamentos desejáveis e indesejáveis, incluindo, neste segundo grupo, as respostas ativas e passivas, possibilitando assim uma dimensão avaliativa em relação ao contexto social.

Após diagnosticar se o instrumento oportunizaria a análise de situações, nas quais os alunos pudessem classificar sua reação, passou-se a avaliar a aplicabilidade do instrumento em relação ao formato do recurso de baixa tecnologia - pranchas, assim como na forma de disposição dos cartões para resposta. Um aspecto que chamou a atenção foi o fato de que, para cada situação, o aluno tinha que dar três respostas. Isto é, o aluno tinha 
http://dx.doi.org/10.5902/1984686X42602

que dar uma resposta de como agiria no lugar do personagem na reação 1, depois na reação 2 e, por último, na reação 3. Apesar de não ter ocorrido nenhuma manifestação de cansaço, percebeu-se que cada movimento motor exigia certo esforço, pois eram cerca de sessenta movimentos em uma mesma tarefa.

Outra consideração foi que os cinco tipos de opções apresentadas, por meio da Escala Likert, para o primeiro grupo experimental, demonstraram ser adequados à faixa etária. Em outras palavras, o aluno tinha que indicar a frequência com que reagiria naquela situação. Com alunos mais jovens, este número de opções poderia contribuir para a falta de atenção, de concentração e de cansaço para a execução da atividade, bem como as opções de resposta com indicação de frequência envolviam um conceito abstrato, não desenvolvido ou desenvolvido parcialmente pelos alunos, e que poderia afetar a compreensão e a avaliação da autopercepção. Discutiu-se que, como os outros instrumentos de avaliação das habilidades sociais utilizam a Escala Likert com variação de 3 a 5 pontos (SMHSC DEL PRETTE; DEL PRETTE, 2005b; IHSA - DEL PRETTE; DEL PRETTE, 2009; THAS-C - BARTHOLOMEU; SILVA; MONTIEL, 2014; SSRS - DEL PRETTE; FREITAS; BANDEIRA, 2016), isto poderia favorecer a tendência central nas respostas dos participantes.

Considerando os aspectos indicados acima, foram retirados os cartões de indicação de frequência e processou-se a leitura direta das situações e solicitação da emissão da resposta por meio do apontar direto para uma das três opções de reações ou a indicação do sime do não quando a examinadora fazia a varredura das alternativas de resposta. Após esta reformulação, conduziu-se o estudo com um segundo grupo experimental para avaliar se o instrumento ficou pertinente às necessidades dos participantes.

\section{4ª Etapa: Segunda aplicação experimental.}

Participaram oito alunos que apresentavam paralisia cerebral ou outra deficiência comprometedora de sua fala articulada. Os alunos demonstravam formas diferentes de sinalizar sua resposta, mostrando com o olhar, o corpo ou com a postura a emissão do sim e do não, a partir da varredura das opções de resposta realizada pela pesquisadora, isto é, em cada item, a criança era solicitada a indicar a reação que costuma apresentar. Estas formas de responder já eram utilizadas de modo sistemático no ambiente escolar. A Figura 3 mostra uma participante que apontava com o pé esquerdo a resposta que retratasse a sua reação e confirmava, caso fosse necessário, colocando o pé direito sobre o outro. 
http://dx.doi.org/10.5902/1984686X42602

Figura 3 - Participante apontando com o pé esquerdo a resposta na prancha

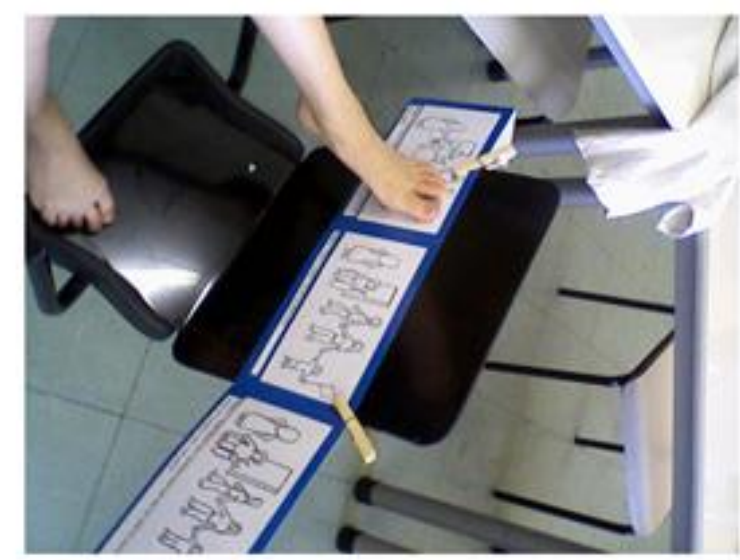

Fonte: arquivo pessoal da primeira autora (2009).

\section{Resultados}

\section{Resultado da primeira aplicação experimental}

Para estimar a concordância entre a autoavaliação e a avaliação das professoras por meio do IHS-ASFA, aplicou-se o Teste de Wilcoxon-Mann-Whitney. Este teste verificou que não houve diferença entre as duas formas de avaliação, para $p \leq 0,02$ (SIEGEL; CASTELLAN, 2006). O tempo médio de aplicação do instrumento foi de 41 minutos e 25 segundos.

\section{Resultado da segunda aplicação experimental}

A expressão facial dos alunos denotou entendimento da tarefa e o tempo médio de aplicação do IHS-ASFA foi de 28 minutos e 12 segundos, sendo inferior ao grupo do primeiro estudo experimental. Analisando-se comparativamente a autopercepção do aluno e a percepção das professoras em relação à tipologia das habilidades sociais, ou seja, comportamento indesejável passivo ou ativo e comportamento desejável, observou-se representativa concordância. Aplicando-se o Teste de Wilcoxon-Mann-Whitney nestes resultados, verificou-se significância estatística, o que demonstra a validade do instrumento (SIEGEL; CASTELLAN, 2006).

Os alunos demonstraram prazer na realização da tarefa, por meio de sorrisos espontâneos e respondendo a esta pergunta diretamente ao final da aplicação do instrumento. Esta aceitação positiva, provavelmente, ocorreu porque as situações 
http://dx.doi.org/10.5902/1984686X42602

condiziam com sua realidade, como mostrou mais claramente a aluna Sandra ao rir das cenas e apontar para o retrato, na sua prancha de Comunicação Alternativa, de um colega de turma que de fato vivenciou aquela cena.

\section{Discussão}

A população com deficiência sem fala articulada, muitas vezes, apresenta dificuldades em diferentes áreas, por conta de encontrar obstáculos no acesso a diferentes pessoas, lugares e objetos para explorá-los e interagir com e sobre eles (LYONS et al., 2016; NUNES, 2003). Assim, estas pessoas são consideradas como não habilidosas (ativas e passivas) pela sociedade, em decorrência de, muitas vezes, não terem voz para emitir seus desejos e pensamentos e vez para colocar-se, visto que normalmente suas necessidades básicas são satisfeitas pelos seus cuidadores, bem como algumas pessoas procuram traduzir o que estas desejam comunicar embora, às vezes, esta interpretação não seja coerente com a intenção real de sua mensagem (QUITERIO; NUNES, 2017; RIBEIRO; PORTO; VANDENBERGHE, 2013; SCHIRMER, 2018).

De acordo com estudos científicos, o ambiente físico da interação, os interlocutores envolvidos e a natureza da relação interpessoal interferem de modo decisivo na utilização do repertório de habilidades sociais e na competência social (DEL PRETTE; DEL PRETTE, 2017; FREITAS; DEL PRETTE, 2013). Devido a este caráter situacional e cultural dos relacionamentos interpessoais, faz-se necessário utilizar diferentes instrumentos e informantes na análise do repertório de habilidades sociais (CABALLO, 2003; DEL PRETTE; DEL PRETTE, 2005b). Mediante isto, teve-se como objetivo principal a construção e avaliação do Inventário de Habilidades Sociais para Alunos Sem Fala Articulada (IHS-ASFA). A elaboração do inventário baseou-se na estrutura conceitual do campo teórico-prático das habilidades sociais e foi motivada, de um lado, pela escassez de instrumentos de avaliação destas habilidades junto a pessoas com deficiência em nosso meio (CARMO, 2019; DEL PRETTE; DEL PRETTE, 2004) e, por outro, pela importância e necessidade de ampliação dos conhecimentos e de intervenção nessa área.

Este estudo vai de encontro com a literatura, pois a primeira etapa, na construção de um instrumento psicológico, deve ser a necessidade de desenvolvimento da escala para atender uma determinada população e, em seguida, a conceituação do construto a ser medido, pois é mediante esta base teórica que os itens do instrumento serão elaborados (BORSA; SEIZE, 2018). Pasquali (1998) recomenda selecionar fontes para o 
http://dx.doi.org/10.5902/1984686X42602

desenvolvimento dos itens do instrumento. O IHS-ASFA utilizou a literatura, bem como a observação direta da população-alvo. Outro aspecto a destacar é que os itens passaram pelo crivo de juízes especialistas, bem como por estudos com grupos experimentais. Essa análise por expertises fornece um retorno ao pesquisador sobre o construto investigado, bem como a relevância do item e sua adequação ao grupo em estudo (PASQUALI, 1998).

Após a aplicação no primeiro grupo experimental, avaliou-se em conjunto com os especialistas, com as professoras e com os próprios participantes que tanto o formato do teste quanto o desenvolvimento dos itens foram adequados às demandas específicas dos alunos com deficiência sem fala articulada. Neste sentido, destaca-se a importância de utilizar recursos alternativos para essa população (HOFF, 2006; QUITERIO; NUNES, 2018; SCHIRMER, 2018), de modo a favorecer as relações interpessoais no contexto escolar e, assim, contribuir com a emissão de comportamentos desejáveis em outros contextos (DEL PRETTE; DEL PRETTE, 2004; ROSIN-PINOLA; DEL PRETTE, 2014).

A construção e análise do instrumento IHS-ASFA teve o propósito de uma análise semântica dos itens (CORDIER et al., 2015). Essa proposta gerou procedimentos como a retirada dos cartões de frequência, substituindo pela classificação direta do comportamento em categorias nominais (desejável, indesejável ativo e indesejável passivo).

O número reduzido de participantes impossibilitou a aplicação de testes paramétricos de significância estatística ou testes de confiabilidade de mudança, o que limitou as conclusões desses resultados, indicando a necessidade de modelos de avaliação mais completos e de aperfeiçoamento metodológico nessa área. Por outro lado, a adequação de um instrumento que possibilitasse a autoperceção, por meio do IHS-ASFA, conseguiu atender aos objetivos, devido às informações relevantes trazidas pelas avaliações dos próprios alunos e das professoras. Destaca-se que elaborar um instrumento para pessoas com deficiência não se resume a um único aspecto, mas envolve cuidados específicos em relação à aplicabilidade e à funcionalidade e considera, como condição indispensável, a heterogeneidade da população com deficiência, incluindo o manuseio e a linguagem utilizada no intrumento, bem como a acessibilidade (BRASIL, 2013; QUITERIO; GERK; NUNES, 2017). Neste sentido, o IHS-ASFA correspondeu a estas normas técnicas em sua construção.

É fundamental ressaltar que este estudo possui um enfoque sensibilizador, inovador e significativo, à medida que avaliou as habilidades sociais de um grupo de pessoas sem fala articulada e, por estar propiciando que estas pessoas estejam envolvidas com o 
processo de investigação, com oportunidades de efetiva interação com o outro, acarretando em uma melhora na qualidade de vida, contribuindo para a inclusão social (MASSARO; DELIBERATO, 2017).

Enfim, espera-se que essa pesquisa contribua como passo inicial da validação do IHSASFA e que tenha continuidade em estudos futuros, com a finalidade de aperfeiçoar e concluir os processos de validação e normatização do inventário e, especialmente, colaborar na avaliação das habilidades sociais de pessoas com deficiência sem fala articulada, de modo a facilitar o planejamento de programas de intervenção em habilidades sociais e, em especial, com a inclusão escolar e social.

\section{Referências}

ALVES, Carolina Abdelnur. Estudos para a construção de uma escala de assertividade para crianças. (Dissertação de Mestrado não publicada). Universidade Gama Filho, Rio de Janeiro, Brasil, 2003.

BARTHOLOMEU, Daniel; SILVA, Marjorie Cristina Rocha; MONTIEL, José Maria. Teste de habilidades sociais para crianças e adolescentes em situação escolar (THAS-C). São Paulo: Memnon, 2014.

BERSCH, Rita. Tecnologia Assistiva. In: SCHIRMER, Carolina Rizzoto. (Org.).

Atendimento Educacional Especializado: deficiência física. São Paulo: MEC/SEESP, 2007, p. 31-40.

BOLSONI-SILVA, Alessandra Turini; LOUREIRO, Sonia Regina; MARTURANO, Edna Maria. Roteiro de Entrevista de Habilidades Sociais Educativas Parentais (RE-HSEP). São Paulo: Vetor, 2011.

BORSA, Juliane Callegaro; SEIZE, Mariana Miranda. Construção e adaptação de instrumentos psicológicos: dois caminhos possíveis. In: DAMÁSIO, Bruno Figueiredo; BORSA, Juliane Callegaro (Org.). Manual de desenvolvimento de instrumentos psicológicos. São Paulo: Vetor, 2018. p. 15-37.

BRASIL. Conselho Federal de Psicologia - CRF. Nota Técnica: Construção, adaptação e validação de instrumentos para pessoas com deficiência. Brasília, DF, 2013. 3p.

BURGEMEISTER, Bessie; BLUM, Lucille Hollander; LORGE, Irving. Escala de Maturidade Mental Columbia: manual para aplicação e interpretação. São Paulo: Casa do Psicólogo, 2001.

CABALLO, Vicente. Elementos componentes da habilidade social. In: CABALLO, Vicente. Manual de avaliação e treinamento das habilidades sociais. São Paulo: Santos, 2003. p. 17-97. 
CARMO, Marwin Machay Indio do Brasil. Caminhos para a validade de um Inventário de Habilidades Sociais para pessoas sem fala articulada. (Monografia de Graduação não publicada). Universidade do Estado do Rio de Janeiro, Rio de Janeiro, 2019.

COHEN, Ronald Jay; SWERDLIK, Mark; STURMAN, Edward. Testagem e avaliação psicológica: introdução a testes e medidas. Porto Alegre: Artes Médicas, 2014.

CORDIER, Reinie. et al. Evaluating the psychometric quality of social skills measures: a systematic review. PLoS ONE, Austrália, n. 10 (7), p. 1-32, jul. 2015.

DEL PRETTE, Almir; DEL PRETTE, Zilda Aparecida Pereira. IHSA: Inventário de habilidades sociais para adolescentes. São Paulo: Casa do Psicólogo, 2009.

DEL PRETTE, Almir; DEL PRETTE, Zilda Aparecida Pereira. Competência Social e Habilidades Sociais. Petrópolis: Vozes, 2017.

DEL PRETTE, Zilda Aparecida Pereira; DEL PRETTE, Almir. Avaliação do repertório social de crianças com necessidades educacionais especiais. In: MENDES, Enicéia Gonçalves; ALMEIDA, Maria Amélia; WILLIAMS, Lúcia Cavalcanti Albuquerque. (Org.). Temas em Educação Especial: avanços recentes. São Carlos: EDUFSCar, 2004. p. 149-157.

DEL PRETTE, Zilda Aparecida Pereira; DEL PRETTE, Almir. Psicologia das habilidades sociais na infância: teoria e Prática. Petrópolis: Vozes, 2005a.

DEL PRETTE, Zilda Aparecida Pereira; DEL PRETTE, Almir. Sistema Multimídia de Habilidades Sociais de Crianças (SMHSC-Del-Prette): manual. São Paulo: Casa do Psicólogo, 2005b.

DEL PRETTE, Zilda Aparecida Pereira; FREITAS, Lucas Cordeiro; BANDEIRA, Marina. Inventário de Habilidades Sociais, Problemas de Comportamento e Competência Acadêmica para Crianças (SSRS-BR2): manual de aplicação, apuração e interpretação. São Paulo: Casa do Psicólogo, 2016.

ELLIOTT, Stephen; GRESHAM, Frank. Social skills intervention guide. Bloomington, MN: Pearson Assessments, 2008.

FAGUNDES, Antônio Jairo. Descrição, definição e registro de comportamento. São Paulo: Edicon, 1985.

FREITAS, Lucas Cordeiro; DEL PRETTE, Zilda Aparecida Pereira. Validade de construto do sistema de avaliação de habilidades sociais para crianças brasileiras com deficiência intelectual. Interamerican Journal of Psychology, Rio Grande do Sul, n. 44(2), p. 312-320, jul. 2010.

FREITAS, Lucas Cordeiro; DEL PRETTE, Zilda Aparecida Pereira. Habilidades sociais de crianças com diferentes necessidades educacionais especiais: avaliação e implicações para intervenção. Avances En Psicología Latinoamericana, Bogotá, n. 31(2), p. 344362, jul. 2013. 
GERALIS, Elaine. Crianças com paralisia cerebral: guia para pais e educadores. 2.ed. Porto Alegre: Artmed, 2007.

GRESHAM, Frank. Social skills assessment and intervention for children and youth.

Cambridge Journal of Education, Reino Unido, n. 46(3), p. 319-332, jul. 2016.

GUTSTEIN, Steven; SHEELY, Rachelle. Relationship development intervention with children, adolescents and adults: social and emotional development activies for asperger syndrome, autismo, PDD and NLD. London: Jessica Kingsley, 2002.

HOFF, Erika. How social contexts support and shape language development. Developmental Review, Florida, n. 26, p. 55-88, mar. 2006.

HUMPHREY, Neil; KALAMBOUKA, Afroditi; WIGELSWORTH, Michael; LENDRUM, Ann; DEIGHTON, Jessica; WOLPERT, Miranda. Measures of social and emotional skills for children and young people: a systematic review. Educational and Psychological Measurement, Reino Unido, n. 71(4), p. 617-637, jun. 2011.

LYONS, Gregory; HUBER, Heartley; CARTER, Erik; CHEN, Rui; ASMUS, Jennifer. Assessing the social skills and problem behaviors of adolescents with severe disabilities enrolled in general education classes. American Journal on Intellectual and Developmental Disabilities, n. 121(4), p. 327-345, jul. 2016.

MASSARO, Munique.; DELIBERATO, Débora. Pesquisas em comunicação suplementar e alternativa na educação infantil. Educação \& Realidade, Porto Alegre, n 42(4), p. 14791501, out./dez. 2017.

NUNES, Leila Regina Oliveira Paula. Favorecendo o desenvolvimento de jovens com necessidades educativas especiais. Rio de Janeiro: Dunya, 2003.

PASQUALI, Luiz. Princípios de elaboração de escalas psicológicas. Revista de psiquiatria clínica, São Paulo, n. 25(5), p. 206-213, 1998.

QUITERIO, Patricia Lorena. Avaliação das habilidades sociais de jovens com paralisia cerebral usuários de comunicação alternativa. Rio de Janeiro: UERJ, 2009.

QUITERIO, Patricia Lorena; GERK, Eliane; NUNES, Leila Regina Oliveira Paula. Avaliação multimodal das habilidades sociais de estudantes com paralisia cerebral usuários de comunicação alternativa. Revista Educação Especial, Santa Maria, n. 30(58), p. 455-470, maio/ago. 2017.

QUITERIO, Patricia Lorena; NUNES, Leila Regina Oliveira Paula. Promoção das habilidades sociais de alunos não falantes tendo como interlocutores graduandas em pedagogia. In: DELIBERATO, Debora; NUNES, Debora Regina Paula; GONÇALVES, Maria Jesus (Org.). Trilhando juntos a Comunicação Alternativa. Marília: ABPEE, 2017. p. 163-180. 
QUITERIO, Patricia Lorena; NUNES, Leila Regina Oliveira Paula. Programa de promoção de habilidades sociais para alunos sem fala articulada. São Paulo: Memnon, 2018.

RIBEIRO, Maysa Ferreira Martins; PORTO, Celmo Celeno; VANDENBERGHE, Luc. Estresse parental em famílias de crianças com paralisia cerebral: revisão integrativa. Ciência e Saúde Coletiva, Rio de Janeiro, n. 18(6), p. 1705-1715, jun. 2013.

ROSIN-PINOLA, Andrea. Regina; DEL PRETTE, Zilda Aparecida Pereira. Inclusão escolar, formação de professores e a assessoria baseada em habilidades sociais educativas. Revista Brasileira de Educação Especial, Bauru, n. 20(3), p. 341-356, jul./set. 2014.

SCHIRMER, Carolina Rizzoto. Comunicação alternativa para alunos com dificuldades severas na fala. Revista Espaço Acadêmico, Paraná, n. 205(18), p. 42-51, jun. 2018.

SIEGEL, S., \& CASTELLAN, N. J. Estatística não-paramétrica para ciências do comportamento. 2. ed. Porto Alegre: Artmed, 2006.

\section{Notas}

1 Sistema de Avaliação de Testes Psicológicos (SATEPSI http://satepsi.cfp.org.br/).

${ }^{2}$ Agradecimento especial ao graduando Marwin Machay Índio do Brasil do Carmo pela participação na análise dos dados quantitativos da pesquisa.

\section{Correspondência}

Patricia Lorena Quiterio - Universidade do Estado do Rio de Janeiro, Instituto de Psicologia, Rua São Francisco Xavier, 524 - sala 10.030E, Maracanã, Rio de Janeiro, Rio Janeiro - Brasil.

CEP: $20550-900$

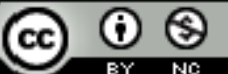

4.0 International (CC BY-NC 4.0) 